Smith, E. E. B., Mills, G. T. \& HARPer, E. M. (1957). J. gen. Microbiol. 16, 426-437

\title{
A Comparison of the Uridine Pyrophosphoglycosyl Metabolism of Capsulated and Non-capsulated Pneumococci
}

\author{
BY EVELYN E. B. SMITH, G. T. MILLS AND \\ ELIZABETH M. HARPER \\ Department of Biochemistry, University of Glasgow, and Department of \\ Bacteriology, University of Glasgow
}

SUMMARY : A study has been made of the uridine pyrophosphoglycosyl compounds present in a non-capsulated pneumococcus (Streptococcus pneumoniae, strain R 19, derived from a type II organism) and a capsulated pneumococcus (type III; Streptococcus pneumoniae, strain A66), and also of certain enzymes involved in the metabolism of these compounds. It has been found that both the pneumococcal strains contained considerable amounts of uridine pyrophosphoglucuronic acid (UPPGA) and uridine pyrophosphoacetylglucosamine (UPPAG), with lesser amounts of uridine pyrophosphoglucose (UPPG), uridine- $5^{\prime}$-monophosphate (UMP), uridine pyrophosphate (UPP) and uridine triphosphate (UTP). The patterns shown by these two strains with respect to uridine nucleotide content were very similar.

Cell-free extracts of strain R 19, derived from a type II organism, were obtained; these extracts contained the following enzymes : glucose-6-phosphate dehydrogenase, uridyl transferase, inorganic pyrophosphatase, nucleoside diphosphokinase, hexokinase and phosphoglucomutase. Examination of the strain A66 capsulated (type III) organism showed the presence of uridyl transferase, nucleoside diphosphokinase and inorganic pyrophosphatase.

It is known that the capsule of type III pneumococci is composed of a polysaccharide whose basic repeating unit is cellobiuronic acid, i.e. glucuronisido-1- $\beta$-4-glucose (Reeves \& Goebel, 1941). To date little is known of the mechanism of formation of polysaccharides whose constituent sugars are other than glucose. There is some evidence, however, that the uridine pyrophosphoglycosyl compounds uridine pyrophosphoglucose (UPPG), uridine pyrophosphoacetylglucosamine (UPPAG) and uridine pyrophosphoglucuronic acid (UPPGA) may be involved in the initial stages of polysaccharide formation. Glaser \& Brown (1955) demonstrated that UPPGA and UPPAG are involved in the overall synthesis of hyaluronic acid by Rous sarcoma, while Mills \& Smith (unpublished observations) have found that the above compounds are participants in the synthesis of the di- and tetrasaccharide units of hyaluronic acid, by using extracts of rat skin or Rous sarcoma. 'The basic steps of synthesis of certain types of polysaccharides may thus be analogous to the formation of sucrose and trehalose phosphate through the mediation of UPPG (Leloir \& Cardini, 1953; Cardini, Leloir \& Chiriboga, 1955; Leloir \& Cabib, 1953).

While it is well known that penumococci have an intense glycolytic metabolism (White, 1938) little is known about the enzymic steps involved in the overall process apart from the recent findings of Marmur \& Hotchkiss (1955) 
which indicated that hexose-6-phosphate isomerase and glucose-6-phosphate dehydrogenase were present in a rough strain $(\mathbf{R 3 6} \mathrm{A})$ derived from a type II organism. The present research is designed to study the carbohydrate metabolism of pneumococci, with particular reference to polysaccharide synthesis by type III pneumococci and the participation of uridine pyrophosphoglycosyl compounds in such synthesis. The metabolic pattern of capsulated type III pneumococci has also been compared with that of non-capsulated organisms derived from a type II pneumococcus.

\section{METHODS}

The organisms used were: (a) A capsulated Streptococcus pneumoniae, type III, strain A66, obtained from the National Collection of Type Cultures. (b) A non-capsulated $S$. pneumoniae, type II, strain R19, kindly supplied by Dr R. D. Hotchkiss, Rockefeller Institute for Medical Research, New York, U.S.A.

Adenosine diphosphate (ADP), triphosphopyridine nucleotide (TPN), $75 \%$ purity, glucose-6-phosphate and hexokinase( type II from yeast) were obtained from Sigma Chemical Company, St Louis, Mo., U.S.A.

Diphosphopyridine nucleotide (DPN), $95 \%$ purity, and glucose-1-phosphate were obtained from C. F. Boehringer and Soehne, Mannheim, West Germany.

Uridine triphosphate (UTP) was obtained from Pabst Laboratories, Milwaukee, Wisconsin, U.S.A.

Bacto Brain Heart Infusion was obtained from Difco Laboratories, Detroit, Michigan, U.S.A.

UPPG and UPPAG were prepared from yeast by the method of Caputto, Leloir, Cardini \& Paladini (1950) and separated by ion exchange and paper chromatography.

UPPGA was isolated from guinea-pig liver (Smith \& Mills, 1954a).

${ }^{32} \mathrm{P}$ labelled inorganic pyrophosphate was prepared from $\mathrm{Na}_{2} \mathrm{H}^{32} \mathrm{PO}_{4}$ (from the Radiochemical Centre, Amersham, England) by the method of Kornberg \& Pricer (1951 $a$ ).

Phosphoglucomutase was prepared and purified from rabbit muscle by the method of Najjar (1948).

\section{Cultivation and harvesting of organisms}

Stock cultures of Streptococcus pneumoniae, type III, strain A66, were maintained on meat-extract $+10 \%(\mathrm{v} / \mathrm{v})$ oxalated horse-blood agar plates; before use the organism was passaged one to three times through mice to ensure good capsule formation, followed by isolation in pure culture on the blood agar medium. The well-capsulated organisms were washed from this plate with sterile $1 \%(\mathrm{w} / \mathrm{v})$ saline and inoculated into requisite volumes of brain heart infusion medium $(3 \cdot 7 \%, \mathrm{w} / \mathrm{v} ; \mathrm{pH} 7 \cdot 4)$ allowing $18 \mathrm{hr}$. growth at $37^{\circ}$ before harvesting; that good capsule formation had occurred was checked by the standard microscopic methods. For enzyme studies, the harvesting of organisms was accomplished by centrifuging at $1500 \mathrm{~g}$ for $15 \mathrm{~min}$. and then

G. Microb. xvi 
re-centrifuging the loosely packed organisms at $10,000 \mathrm{~g}$ for $15 \mathrm{~min}$. to obtain a tightly packed mass. For nucleotide analysis the organism was grown in $4 \mathrm{l}$. batches of brain heart infusion medium, incubated at $37^{\circ}$ for $18 \mathrm{hr}$. and formaldehyde solution $(40 \%, \mathrm{w} / \mathrm{v})$ to a final concentration of $1 \%(\mathrm{w} / \mathrm{v})$ was then added; the culture was centrifuged in a Sharples Super Centrifuge $15 \mathrm{~min}$. after the addition of formaldehyde and the pneumococcal paste suspended in the minimum volume of distilled water. Boiling water extracts for nucleotide analysis were made by pouring the suspension of organisms obtained from each $4 \mathrm{l}$. batch into $100 \mathrm{ml}$. vigorously boiling water; boiling was continued for $1 \mathrm{~min}$. and the suspension then rapidly cooled at $-15^{\circ}$ until a temperature of $0^{\circ}$ was attained. Bacterial debris was removed by filtration. Stock cultures of the non-capsulated R 19 strain of Streptococcus pneumoniae were also maintained on meat-extract thorse-blood $(10 \%, \mathrm{v} / \mathrm{v})$ agar plates. Before mass cultivation of organisms for nucleotide analysis, two daily subcultures were made in brain heart infusion medium $(3.7 \%, \mathrm{w} / \mathrm{v} ; \mathrm{pH} \mathbf{7 \cdot 4})$. Harvesting for nucleotide analysis and enzyme studies was accomplished by a single centrifugation at $1500 \mathrm{~g}$ for $20 \mathrm{~min}$. Boiling water extracts were made as described for the A66 strain.

Paper chromatography of the nucleotides was carried out as previously described by Smith \& Mills (1954a). Paper chromatography of sugars was carried out with the butanol/acetic acid/water solvent of Partridge (1948) and the ethanol/ammonium acetate solvent of Paladini \& Leloir (1952) as described for nucleotide chromatography. The sugar spots were developed by the silver nitrate method of Trevelyan, Procter \& Harrison (1950).

\section{RESULTS}

\section{Uridine nucleotide analysis}

Nucleotide analysis of the boiling water extracts of the $\mathbf{R} 19$ and $A 66$ strains was confined to the uridine derivatives. The filtered aqueous extracts were adjusted to $\mathrm{pH} 9$ with ammonia and applied to Dowex $1 \mathrm{Cl}^{\prime}$ columns $(10 \mathrm{~cm} . \times 1 \mathrm{~cm}$. diameter for extracts obtained from a 4 1. culture). The columns were washed with $50 \mathrm{ml}$. distilled water and developed with solutions containing increasing concentrations of $\mathrm{HCl}$ and $\mathrm{NaCl}$, namely:

$$
\begin{aligned}
& 0.01 \mathrm{~N}-\mathrm{HCl}+0.01 \mathrm{M}-\mathrm{NaCl} ; 0.01 \mathrm{~N}-\mathrm{HCl}+0.03 \mathrm{M}-\mathrm{NaCl} ; \\
& 0.01 \mathrm{~N}-\mathrm{HCl}+0.05 \mathrm{M}-\mathrm{NaCl} ; 0.01 \mathrm{~N}-\mathrm{HCl}+0.2 \mathrm{M}-\mathrm{NaCl} \text {. }
\end{aligned}
$$

Each of the eluted fractions was collected in bulk and treated by the charcoal adsorption and elution method as described by Smith \& Mills (1954b) before chromatography in the ethanol/ammonium acetate solvent. As will be seen from Fig. 1 both the capsulated (A66) and non-capsulated (R 19) strains of pneumococci possess the uridine nucleotides UMP, UPPG, UPPGA, UPP and UTP. These nucleotides were eluted from the paper chromatograms and specifically identified by the enzymic and hydrolytic methods described by Smith \& Mills (1954a).

Both strains of pneumococci also contained material chromatographically identical with UPPAG which, on hydrolysis with $0.01 \mathrm{~N}-\mathrm{H}_{2} \mathrm{SO}_{4}$ for $10 \mathrm{~min}$. 
yielded UPP and a sugar corresponding to acetylglucosamine in the solvents of Partridge (1948) and of Paladini \& Leloir (1952). The positions of some sugars in this latter solvent, hitherto used only for nucleotides, are shown in Fig. 2.

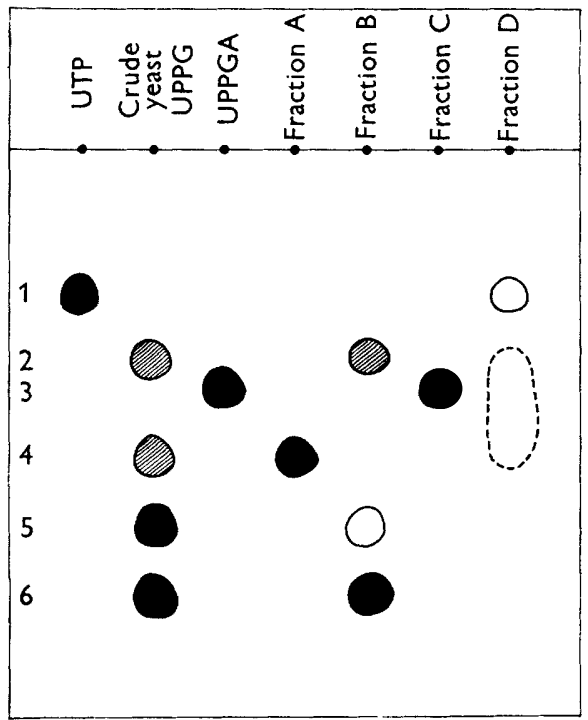

Fig. 1

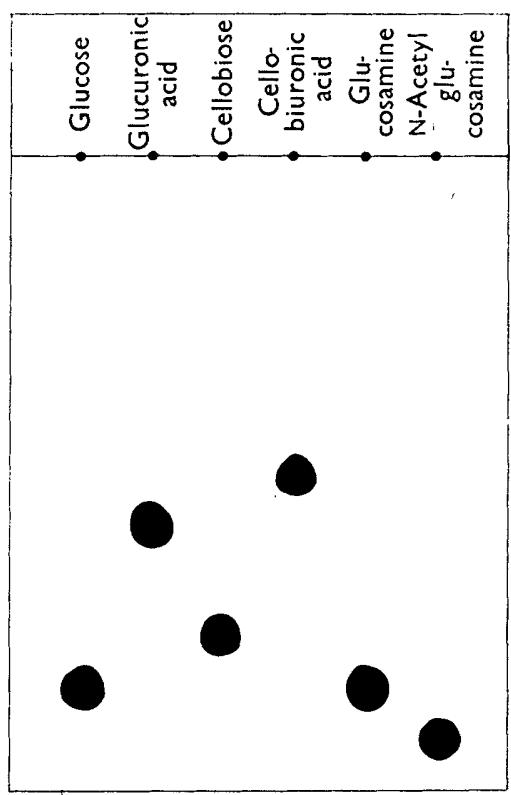

Fig. 2

Fig. 1. Paper chromatography of Dowex $1 \mathrm{Cl}^{\prime}$ column fractions from aqueous extracts of Streptococcus pneumoniae, strain R19 (derived from a type II organism), and $S$. pneumoniae, strain A66 (type III). Whatman no. 1 acid-washed paper and ethanol/ ammonium acetate solvent containing $10^{-2} \mathrm{M}$-versene were used, and the chromatograms developed for $24 \mathrm{hr}$. Column eluate fractions were treated as described in text. Fraction $\mathrm{A}=0.01 \mathrm{~N}-\mathrm{HCl}+0.01 \mathrm{~m}-\mathrm{NaCl}$ eluate; fraction $\mathrm{B}=0.01 \mathrm{~N}-\mathrm{HCl}+0.03 \mathrm{~m}-\mathrm{NaCl}$ eluate; fraction $\mathrm{C}=0.01 \mathrm{~N}-\mathrm{HCl}+0.05 \mathrm{M}-\mathrm{NaCl}$ eluate; fraction $\mathrm{D}=0.01 \mathrm{~N}-\mathrm{HCl}+0.2 \mathrm{M}-$ NaCl eluate. 1, UTP; 2, UPP; 3, UPPGA ; 4, UMP; 5, UPPG; 6, UPPAG. A crude ycast UPPG preparation, pure UTP and pure liver UPPGA were used as markers. Intensity of shading of the spots is an indication of the relative amounts of nucleotides present.

Fig. 2. Paper chromatography of some sugars in ethanol/ammonium acetate solvent on Whatman no. 1 paper; development for $18 \mathrm{hr}$.

The proportional distribution of the uridine nucleotides was comparable in the two strains after $18 \mathrm{hr}$. of growth; the relative percentage distribution of the uridine nucleotides in the strains may be designated as follows: UPPAG $35 \%$, UPPGA $30 \%$, UPPG $7 \%$, UTP $7 \%$, UPP $7 \%$ and UMP $14 \%$. Of the total nucleotides present in the organisms, uridine exceeded adenine in the ratio of $2: 1$.

The enzymes of the uncapsulated strain $R 19$ of Streptococcus pneumoniae

Several conventional methods for disrupting micro-organisms were tested in an attempt to obtain cell-free preparations for enzyme studies. Lysozyme as used under the conditions specified by Welshimer (1953) for Bacillus 
megaterium failed to disrupt the organism. While Triton X100 $(0 \cdot 1 \%, \mathrm{w} / \mathrm{v}$; Rohm and Hass Co., Philadelphia, Penn., U.S.A.) and bile salts ( $1 \%$, w/v, final concentration) dissolved the organism, most of the enzymes under study were irreversibly inactivated by these processes. Freezing and thawing in an ice + salt mixture was also ineffective; the use of ethanol + solid $\mathrm{CO}_{2}$ for the freezing and thawing technique was successful in breaking down the pneumococci but several enzymes under study were inactivated in the process. The most consistently effective method of disruption was to grind the organisms by hand mortar and pestle in the presence of ballotini (no. 12) and buffers of specific $\mathrm{pH}$ values. The use of ballotini in the Mickle disintegrator resulted in considerable loss of enzyme activity.

The centrifuged organisms of the $\mathbf{R} 19$ strain (from $50 \mathrm{ml}$. culture medium) were suspended in three times their weight of $\mathrm{m} / \mathbf{1 5}$ phosphate buffer $(\mathrm{pH} \mathrm{6 \cdot 6)}$, ground in a glass mortar for $\mathbf{2 0}$ min. with ten times their weight of ballotini, allowed to stand at $0^{\circ}$ for 1-2 hr. and re-ground for $10 \mathrm{~min}$. The extract was centrifuged at room temperature until clear $(10,000 \mathrm{~g}$ for $5 \mathrm{~min}$.) and the following enzymes were shown to be present.

Glucose-6-phosphate dehydrogenase. The method of Kornberg \& Pricer (1951b) was used for the assay of this enzyme, with the results shown in Fig. 3.

Uridyl transferase. The presence of an active uridyl transferase was shown by the following reactions:

(1) UTP $+\alpha$-glucose-1-phosphate $\rightarrow$ UPPG + pyrophosphate;

(2) UPPG + pyrophosphate- $\rightarrow$ UTP $+\alpha$-glucose-1-phosphate.

The products of reaction 1 were identified chromatographically by methods previously described (Munch-Petersen, Kalckar, Cutolo \& Smith, 1953; Smith $\&$ Mills, 1954 $a$ ) and the result is shown in Fig. 4. In the normal course of reaction 1 it is essential to add purified extraneous inorganic pyrophosphatase to remove the pyrophosphate formed; it was found however that the pneumococcal extract contained a very potent inorganic pyrophosphatase, allowing the reaction to proceed to the extent shown in Fig. 4.

Reaction 2 was assayed enzymically (Munch-Petersen, Kalckar \& Smith, 1955) with the results shown in Fig. 5. Further confirmation of the existence of this reaction was obtained chromatographically by using ${ }^{32} \mathbf{P}$-labelled inorganic pyrophosphate as shown in Fig. 6 .

In the assay described in Fig. 5, the reaction was triggered with pyrophosphate; it was necessary however to add UPPG to the bacterial extract before adding phosphoglucomutase; when the phosphoglucomutase was added before the UPPG, the overall rate of reaction was decreased by $c .60 \%$. This effect may be due to a competitive inhibition of the uridyl transferase system by a factor present in the phosphoglucomutase preparation.

Pure UPPAG was also pyrophosphorolysed by the enzyme extract to yield ${ }^{32} \mathrm{P}$-labelled UTP; this result is shown in Fig. 6. It was also possible to demonstrate this reaction spectrophotometrically using the method employed by Mills, Ondarza \& Smith (1954) for the pyrophosphorolysis of UPPAG by liver 
nuclei extracts. In the present case, $0 \cdot 1 \mu$ mole UPPAG gave a $\Delta E_{\mathbf{3 4 0}}$ value of 0.50 in $30 \mathrm{~min}$. in the presence of $200 \mu \mathrm{l}$. pneumococcal extract.

Inorganic pyrophosphatase. A $25 \mu \mathrm{l}$. sample of a typical pneumococcal extract completely hydrolysed $1 \mu$ mole inorganic pyrophosphate to orthophosphate in 15 min. at $25^{\circ}$. In brain heart infusion medium the $\mathbf{R} 19$ pneumococcus strain was capable of growing in the presence of added inorganic pyrophosphate at concentrations of the latter up to $0.002 \mathrm{M}$; above this value growth ceased.

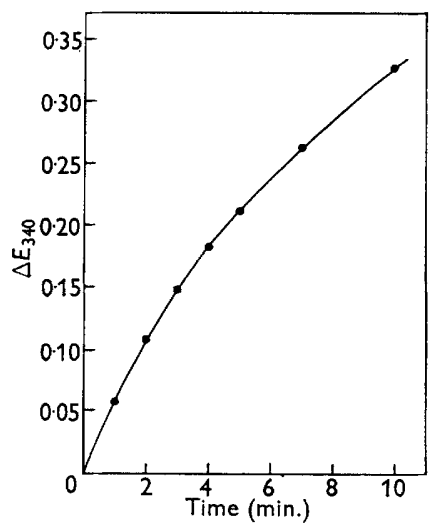

Fig. 3

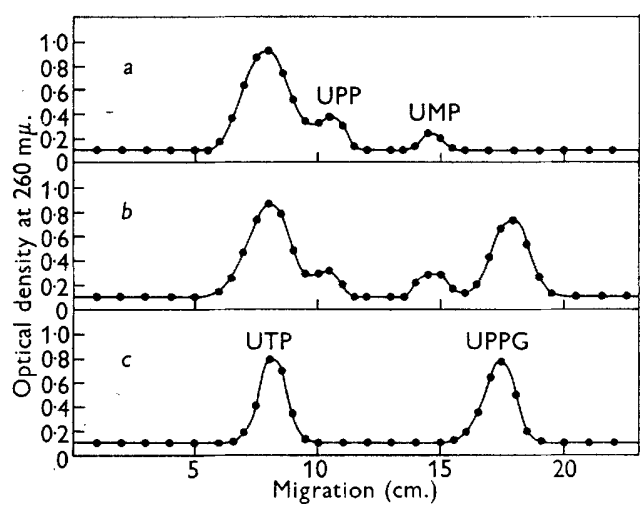

Fig. 4

Fig. 3. The glucose-6-phosphate dehydrogenase activity of an extract of Streptococcus pneumoniae, strain R19 (derived from a type II organism). The incubation mixture consisted of: $0 \cdot 1 \mathrm{M}$-Tris buffer $(\mathrm{pH} \mathrm{7.8}) ; 5 \mu$ mole $\mathrm{MgCl}_{2} ; 50 \mu \mathrm{l}$. pneumococcal extract; $0 \cdot 1 \mu$ mole glucose-6-phosphate; $0 \cdot 25 \mu$ mole TPN; total volume $1.0 \mathrm{ml}$. Control cuvettes were used simultaneously in which glucose-6-phosphate or pneumococcal extract were omitted; the experimental $\boldsymbol{E}_{340}$ values were corrected for these blank values.

Fig. 4. The formation of UPPG by an extract of Streptococcus pneumoniae, strain $\mathbf{R} 19$ (derived from a type II organism). (a) $2 \mu$ mole UTP; $5 \mu$ mole $\mathrm{MgCl}_{2}, 400 \mu \mathrm{l}$. pneumococcal extract and $0 \cdot 1 \mathrm{M}$-Tris buffer $(\mathrm{pH} \mathrm{7 \cdot 8}$ ) to a final volume of $2 \mathrm{ml}$.; mixture incubated for $30 \mathrm{~min}$. at $25^{\circ}$. (b) The same as $(a)$ with the addition of $5 \mu \mathrm{mole} \alpha$-glucose-1phosphate. Reaction stopped and protein removed with $200 \mu \mathrm{l} .10 \%(\mathrm{w} / \mathrm{v})$ perchloric acid and centrifugation. Subsequent charcoal adsorption, elution and chromatography of the nucleotides in the ethanol/ammonium acetate solvent was carried out as described by Smith \& Mills (1954a). Chromatograms were scanned in the Unicam S.P. 500 spectrophotometer at $260 \mathrm{~m} \mu$. (c) Pure marker substances chromatographed simultaneously.

Nucleoside diphosphokinase. Nucleoside diphosphokinase, catalysing the reaction UTP + ADP $\rightleftharpoons$ UPP + ATP (described by Berg \& Joklik, 1954, for yeast and rabbit muscle) was shown to be present in the pneumococcus $\mathbf{R} 19$ extract by chromatographic means; data for this experiment are shown in Fig. 7.

Hexokinase. Extraction of hexokinase was achieved by grinding the organisms with $\mathrm{m} / \mathbf{1 5}$ phosphate buffer ( $\mathrm{pH} 6 \cdot 6$ ). The assay was conducted spectrophotometrically by the method of Slein, Cori \& Cori (1950) and the results are indicated in Fig. 8.

Phosphoglucomutase. While buffered extracts of the R19 strain of pneumococcus did not yield a very active phosphoglucomutase preparation, the 
enzyme was nevertheless shown to be present by the conversion of glucose-1phosphate to glucose-6-phosphate, the production of the latter being determined by the spectrophotometric method of Kornberg \& Pricer (1951 $b$ ). Figure 9 records the data for this reaction.

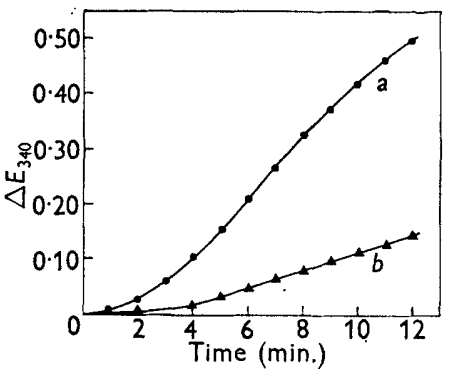

Fig. 5

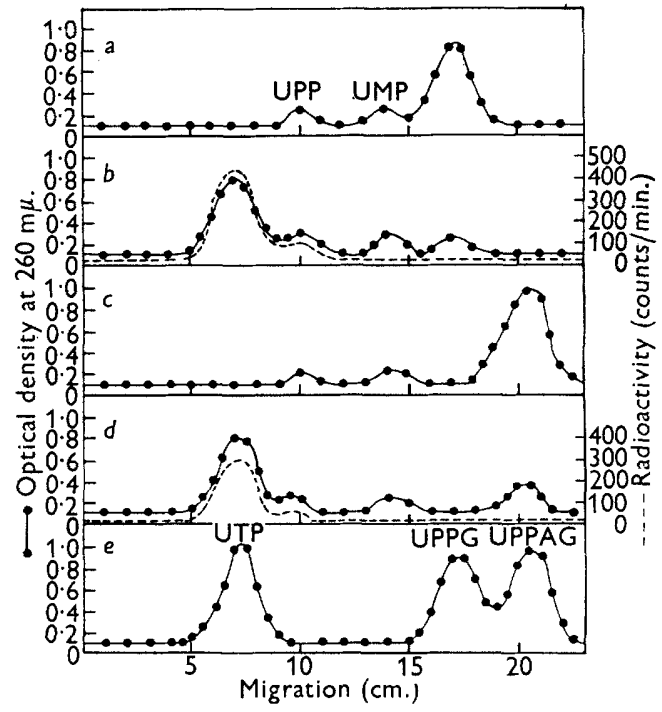

Fig. 6

Fig. 5. The pyrophosphorolysis of UPPG by an extract of Streptococcus pneumoniae, strain R 19 (derived from a type II organism). $0 \cdot 3 \mu$ mole UPPG was incubated with $100 \mu \mathrm{I}$. pneumococcal extract, and $5 \mu$ mole $\mathrm{MgCl}_{2}, 0 \cdot 25 \mu$ mole TPN, $2 \cdot 5 \mu$ mole cysteine, $30 \mu \mathrm{l}$. phosphoglucomutase preparation, 1.0 $\mu$ mole potassium pyrophosphate, $0 \cdot 1 \mathrm{M}$-Tris

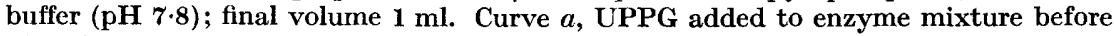
phosphoglucomutase. Curve $b$, UPPG added to enzyme mixture after phosphoglucomutase. Reaction started with pyrophosphate in both cases. Control cuvettes were run simultaneously, in which UPPG or pneumococcal extract were omitted; experimental $\boldsymbol{E}_{340}$ values were corrected for these blank values.

Fig. 6. The pyrophosphorolysis of UPPG and UPPAG by extracts of Streptococcus pneumoniae, strain R19 (derived from a type II organism). (a) $2 \mu$ mole UPPG incubated with $5 \mu$ mole $\mathrm{MgCl}_{2}, 400 \mu \mathrm{l}$. pneumococcal extract and $0 \cdot 1 \mathrm{M}$-Tris buffer to a final volume of $2 \mathrm{ml}$, for $30 \mathrm{~min}$. at $25^{\circ}$. (b) Same as $(a)$ with the addition of $5 \mu$ mole potassium pyrophosphate labelled with ${ }^{32} \mathbf{P}(1 \mu \mathrm{c}$.). (c) Same as $(a)$ with $2 \mu$ mole UPPAG replacing the UPPG. (d) Same as (b) with $2 \mu$ mole UPPAG replacing the UPPG. Reaction mixtures treated as Fig. 4. In reactions $(b)$ and $(d)$ the charcoal used was previously washed with inorganic phosphate and pyrophosphate. (e) Pure marker substances chromatographed simultaneously. In addition to scanning at $260 \mathrm{~m} \mu$. in the Unicam S.P. 500 spectrophotometer, the chromatograms were scanned for radioactivity as previously described (Smith \& Mills, 1954a).

The most effective $\mathrm{pH}$ value for the extraction of the above mixture of enzymes from the non-capsulated $\mathrm{R} 19$ pneumococei was $\mathrm{pH}$ 6.6. Small differences in acidity or alkalinity effectively decreased the extractive properties of the buffer. When, however, R19 pneumococci were ground with distilled water in the manner described, glucose-6-phosphate dehydrogenase could be selectively extracted. This is particularly useful in view of the desirability of 
having a glucose-6-phosphate dehydrogenase preparation free from uridyl transferase, since the majority of preparations of the former usually have an associated uridyl transferase. Such a bacterial extract should thus be of considerable use in determining the presence or absence of uridyl transferase in various tissues.

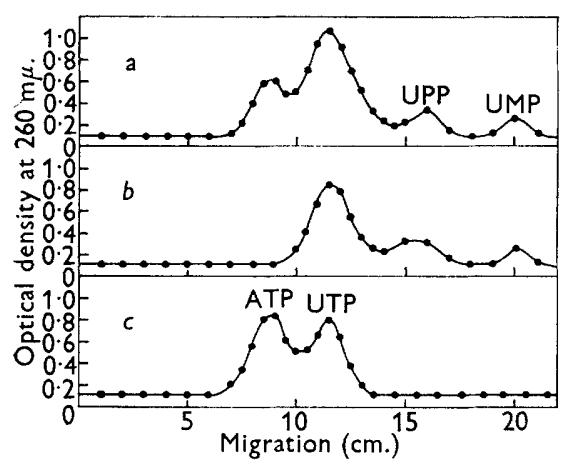

Fig. 7

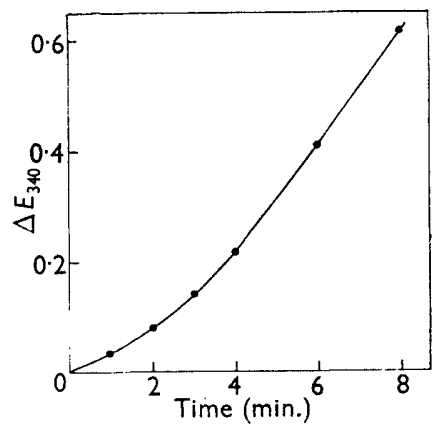

Fig. 8

Fig. 7. The formation of ATP from UTP and ADP by an extract of Streptococcus pneumoniae, strain R 19 (derived from a type II organism). (a) $1 \mu$ mole UTP incubated with $5 \mu$ mole $\mathrm{MgCl}_{2}, 150 \mu \mathrm{l}$. pneumococcal extract, $1 \mu \mathrm{mole}$ ADP and $0 \cdot 1 \mathrm{M}-$ Tris buffer $(\mathrm{pH} \mathbf{7} \cdot 8$ ) to a final volume of $1 \mathrm{ml}$., for $30 \mathrm{~min}$. at $25^{\circ}$. (b) Same as (a) without the addition of ADP. Reaction mixture treated as in Fig. 4. (c) Pure marker substances chromatographed simultaneously.

Fig. 8. The hexokinase activity of an extract of Streptococcus pneumoniae, strain $\mathbf{R} 19$ (derived from a type II organism). The incubation mixture consisted of : $100 \mu \mathrm{l}$. pneumococcal extract; $5 \mu$ mole $\mathrm{MgCl}_{2} ; 0.25 \mu$ mole TPN; $1 \mu$ mole glucose; $0.2 \mu$ mole ATP; $0.1 \mathrm{~m}$-Tris buffer $\mathrm{pH} 7.8$ to a final volume of $1 \mathrm{ml}$. Control cuvettes were run simultaneously in which ATP or pneumococcal extract were omitted; the experimental $\boldsymbol{E}_{340}$ values were corrected for these blank values.

From the results recorded in Fig. 4 and 6 it is apparent that there was very little breakdown of UTP to UPP or UMP. When, however, $0 \cdot 1$ M-maleate buffer ( $\mathrm{pH} \mathrm{6 \cdot 6)}$ was substituted for phosphate buffer in the extraction procedure, UTP was readily broken down to diphosphate and monophosphate under the conditions specified in Fig. 4.

\section{Enzymes of Streptococcus pneumoniae, type III, strain A66}

The problem of obtaining an active enzyme extract from Streptococcus pneumoniae, strain A66, is made more difficult by the capsules which surround the organisms. So far it has proved impossible to disrupt these pneumococci by any of the methods tested with the uncapsulated strain $R 19$; in consequence all enzyme studies have been made with intact organisms. The wet packed organisms $(10,000 \mathrm{~g}, 15 \mathrm{~min}$.) were suspended in an equal volume of appropriate buffer and this suspension used in the enzyme experiments. The following enzymes associated with uridine pyrophosphoglycosyl metabolism were shown to be present. 
Uridyl transferase. Using ${ }^{32} \mathrm{P}$-labelled pyrophosphate, pyrophosphorolysis of UPPG to UTP was effectively accomplished by whole cells. The end products of the reaction were identified chromatographically; full data for the experiment are shown in Fig. 10. The UTP formed in the reaction was eluted from paper and further identified by the enzymic assay of Berg \& Joklik (1954).

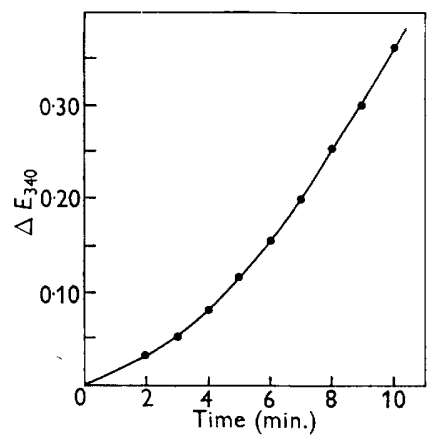

Fig. 9

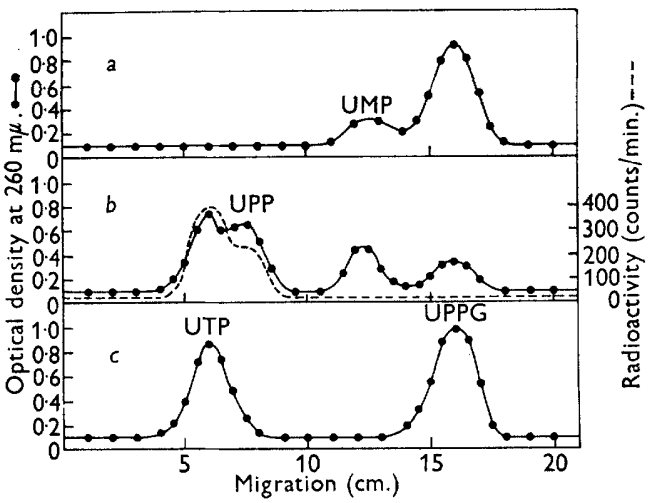

Fig. 10

Fig. 9. The phosphoglucomutase activity of an extract of Streptococcus pneumoniae, strain R19 (derived from a type II organism). The incubation mixture contained: $200 \mu \mathrm{l}$. pneumococcal extract; $0 \cdot 1 \mu$ mole glucose-1-phosphate ; $\mu$ mole $\mathrm{MgCl}_{2} ; 2 \cdot 5 \mu$ mole cysteine ; $0.25 \mu$ mole TPN; $0 \cdot 1 \mathrm{M}$-Tris buffer $\mathrm{pH} 7 \cdot 8$ to a final volume of $1 \mathrm{ml}$. Control cuvettes were run simultaneously in which glucose-1-phosphate or pneumococcal extract were omitted; the $E_{340}$ values were corrected for these blank values.

Fig. 10. The pyrophosphorolysis of UPPG by a suspension of Streptococcus pneumoniae, type III, strain A66. (a) $3 \mu$ mole UPPG incubated with $10 \mu$ mole $\mathrm{MgCl}_{2}, 0.5 \mathrm{ml}$.

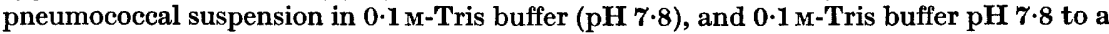
final volume of $1.5 \mathrm{ml}$. (b) Same as $(a)$ with the addition of $5 \mu$ mole potassium pyrophosphate labelled with ${ }^{32} \mathrm{P}(1 \mu \mathrm{c}$.). Reaction mixtures treated as in Fig. 6. (c) Pure marker substances chromatographed simultaneously.

Nucleoside diphosphokinase. This enzyme was shown to be present in the whole cells by chromatographic means; the method employed was identical with that described in Fig. 7 with, however, the substitution of $0.5 \mathrm{ml}$. pneumococcal type III suspension for the extract used in the case of the uncapsulated R19 strain. The results obtained were essentially similar to those shown in Fig. 7.

Inorganic pyrophosphatase. As with strain R19, the formation of UPPG from UTP and $\alpha$-glucose-1-phosphate by the capsulated A66 pneumococci proceeded without the addition of extraneous inorganic pyrophosphatase; an active inorganic pyrophosphatase was found in the intact organisms of strain A66. When grown in brain heart infusion medium it was apparent that the capsulated and non-capsulated pneumococci were identical with respect to pyrophosphate tolerance, the capsulated A66 strain growing at all concentrations of pyrophosphate up to $0.002 \mathrm{M}$; above this figure growth again ceased entirely. 


\section{DISCUSSION}

While comparatively little is known of the mechanism of synthesis of polysaccharides other than those containing only glucose, it is not improbable (see introduction) that such synthesis may be mediated through the uridine pyrophosphoglycosyl compounds. The uridine pyrophosphoglycosyl metabolism of the pneumococci used here may well bear some relation to the synthesis of the constituent polysaccharides. The only known mechanism for the intramolecular transfer of glucuronic acid is that mediated by UPPGA (Smith \& Mills, 1954 $a$; Mills \& Smith, 1955), and it is conceivable, in view of the presence of this compound in the pneumococci, that UPPGA may act as a transferring agent for glucuronic acid. In the metabolism of type III pneumococci the glucuronic acid acceptor may well be glucose, giving rise to the repeating disaccharide unit of the capsular polysaccharide.

In view of the fact that both the capsulated and non-capsulated strains contain virtually identical enzyme systems of uridine nucleotide metabolism and also exhibit the same pattern of uridine nucleotide distribution, it is possible that the difference in their ability to produce the capsular polysaccharide resides in a subsequent conjugation step or an even later polymerization step.

It has been shown above that both the strains of pneumococcus used contain considerable amounts of UPPAG. Since the type III capsular polysaccharide is completely devoid of acetylglucosamine, the uridine derivative of this sugar may be involved in the synthesis of the cellular polysaccharide as distinct from the capsular polysaccharide. Preliminary studies by the present authors on the sugar composition of the cellular polysaccharide of strain R 19 derived from a type II organism, have indicated that this material is rich in glucosamine which is possibly the $\mathrm{N}$-acetyl derivative.

It was shown by Strominger, Kalckar, Axelrod \& Maxwell (1954) that the mechanism of formation of UPPGA by liver tissue occurs by means of a DPNlinked oxidation of UPPG. The presence of an active system for the synthesis of UPPG in both strains of pneumococci suggests that UPPGA may well be derived from UPPG in these micro-organisms. It has not yet proved possible to demonstrate conclusively the presence of a UPPG oxidase which causes the formation of UPPGA in these bacteria; this, however, does not preclude the possibility that such an enzyme system exists.

While it has been possible to obtain cell-free enzyme systems from the noncapsulated R19 strain (derived from type II) by fairly simple methods, the capsulated A66 strain (type III) has remained resistant to the techniques employed; the difficulty in disrupting this strain is probably due to the presence of the capsule. A method which may yield the desired results would be a removal of the capsule by a specific enzyme technique; Sickles \& Shaw (1934) and Dubos (1935) obtained enzyme preparations from Bacillus palustris and a similar organism, which were capable of hydrolysing specifically the type III pneumococcal capsular polysaccharide; this would prove a useful tool in rendering the organism more liable to disruption. The principles set out above will be the basis of further investigations. 
One of us (E.E.B.S.) is the holder of a Beit Memorial Fellowship for Medical Research.

The expenses of this research were defrayed in part by a grant from the Medical Research Council, and in part by the Rankin Fund of the University of Glasgow, both of which we acknowledge with thanks. The authors wish to thank Mr Brian Galloway for excellent technical assistance.

\section{REFERENCES}

BERG, P. \& JokLIK, W. K. (1954). Enzymatic phosphorylation of nucleoside diphosphates. J. biol. Chem. 210, 657.

Caputto, R., Leloir, L. F., Cardini, C. E. \& Paladini, A. C. (1950). Isolation of the coenzyme of the galactose phosphate-glucose phosphate transformation. J. biol. Chem. 184, 333.

Cardini, C. E., Leloir, L. F. \& Chiriboga, J. (1955). The biosynthesis of sucrose. J. biol. Chem. 214, 149.

Dubos, R. (1935). Studies on the mechanism of production of a specific bacterial enzyme which decomposes the capsular polysaccharide of type III pneumococcus. J. exp. Med. 62, 259.

Graser, L. \& Brown, D. H. (1955). The enzymatic synthesis in vitro of hyaluronic acid chains. Proc. nat. Acad. Sci., Wash. 41, 253.

Kornberg, A. \& Pricer, W. E. (1951 $a$ ). Enzymatic cleavage of diphosphopyridine nucleotide with radioactive pyrophosphate. J. biol. Chem. 191, 535.

Konnberg, A. \& Pricer, W. E. (1951 b). Enzymatic phosphorylation of adenosine and 2:6-diamino purine riboside. J. biol. Chem. 193, 481.

Leloir, L. F. \& Cabib, E. (1953). The enzymic synthesis of trehalose phosphate. J. Amer. chem. Soc. 75, 5445.

Leloir, L. F. \& Cardini, C. E. (1953). The biosynthesis of sucrose. J. Amer. chem. Soc. 75, 6084.

MARMUR, J. \& Hotchkiss, R. D. (1955). Mannitol metabolism, a transferable property of the pneumococcus. J. biol. Chem. 214, 383.

Mills, G. T., Ondarza, R. \& Smith, E. E. B. (1954). The uridyl transferase of liver. Biochim. biophys. Acta, 14, 159.

MrLls, G. T. \& SMITH, E. E. B. (1955). Enzymic conversion of glycogen and starch to glucuronides. Fed. Proc. 14, 256.

Munch-Petersen, A., Kalckar, H. M., Cutolo, E. \& Smith, E. E. B. (1953). Enzymic production of uridine triphosphate: uridine diphosphoglucose pyrophosphorolysis. Nature, Lond. 172, 1036.

Munch-Petersen, A., Kalckar, H. M. \& Smith, E. E. B. (1955). Uridyl transferases their occurrence and physiological role. Biol. Medd. Kbh. 22, no. 7 .

NaJJar, V. A. (1948). The isolation and properties of phosphoglucomutase. J. biol. Chem. 175, 281.

Paladini, A. C. \& Lelotr, L. F. (1952). Studies on uridine diphosphate glucose. Biochem. J. 51, 426.

PARTridge, S. M. (1948). Filter paper chromatography of sugars. Biochem. J. 42, 238.

Reeves, R. E. \& Goeber, W. F. (1941). The structure of the type III polysaccharide. J. biol. Chem. 139, 511.

Sickles, G. M. \& Shaw, M. (1934). A systematic study of the micro-organisms which decompose the specific carbohydrate of the pneumococcus. J. Bact. $28,415$.

Slein, M. W., Cori, G. T. \& Cori, C. F. (1950). A comparative study of hexokinase from yeast and animal tissues. J. biol. Chem. 186, 763.

Smith, E. E. B. \& Mills, G. T. (1954a). Uridine nucleotide compounds of liver. Biochim. biophys. Acta, 13, 386.

Sмiтн, E. E. B. \& MirLs, G. T. (1954b). Nucleotide components of the mammary gland. Biochim. biophys. Acta. 13, 587. 
Strominger, J. L., Kalckar, H. M., Axelrod, J. \& Maxwell, E. S. (1954). Enzymic oxidation of uridine diphosphate glucose to uridine diphosphoglucuronic acid. J. Amer. chem. Soc. 76, 6411.

Trevelyan, W. E., Procter, D. P. \& Harrison, J. S. (1950). Detection of sugars on paper chromatograms. Nature, Lond. 166, 444.

Welshimer, H. J. (1953). The action of lysozyme on the cell wall and capsule of Bacillus megaterium. J. Bact. 66, 112.

White, B. (1938). Biology of the Pneumococcus. New York: Commonwealth Fund.

(Received 17 October 1956) 